\title{
Shear localisation in anisotropic, non-linear viscous materials that develop a CPO: a numerical study
}

Tamara de Riese ${ }^{\mathrm{a},{ }^{*}}$, Lynn Evans ${ }^{\mathrm{b}}$, Enrique Gomez-Rivas ${ }^{\mathrm{c}, \mathrm{d}}$, Albert Griera ${ }^{\mathrm{e}}$, Ricardo A. Lebensohn ${ }^{\mathrm{f}}$, Maria-Gema Llorens ${ }^{\mathrm{e}}$, Hao Ran ${ }^{\mathrm{a}, \mathrm{g}}$, Till Sachau ${ }^{\mathrm{a}}$, Ilka Weikusat ${ }^{\mathrm{h}}$, Paul D. Bons $^{\mathrm{a}}$

${ }^{a}$ Department of Geosciences, Eberhard Karls University Tübingen, Tübingen, Germany

${ }^{\mathrm{b} S c h o o l ~ o f ~ E a r t h, ~ A t m o s p h e r e ~ a n d ~ E n v i r o n m e n t a l ~ S c i e n c e s, ~ M o n a s h ~ U n i v e r s i t y, ~ C l a y t o n, ~ V i c t o r i a, ~}$ Australia

${ }^{\mathrm{c} D e p a r t m e n t ~ o f ~ M i n e r a l o g y, ~ P e t r o l o g y ~ a n d ~ A p p l i e d ~ G e o l o g y, ~ U n i v e r s i t y ~ o f ~ B a r c e l o n a, ~ B a r c e l o n a, ~}$ Spain

${ }^{\mathrm{d}}$ School of Geosciences, King's College, University of Aberdeen, Aberdeen, UK

e'Departament de Geologia, Universitat Autònoma de Barcelona, Barcelona, Spain

${ }^{f}$ Theoretical Division, Los Alamos National Laboratory, USA

${ }^{\mathrm{g}}$ School of Earth Sciences and Resources, China University of Geosciences, Beijing, China

${ }^{\mathrm{h}}$ Alfred Wegener Institute for Polar and Marine Research, Bremerhaven, Germany

*Corresponding author: Department of Geosciences, Eberhard Karls University, Wilhelmstraße 56, 72074 Tübingen, Germany. Tel.: +49-7071-29-73147

tamara.de-riese@uni-tuebingen.de

This manuscript is published in the Journal of Structural Geology (2019), vol. 124, 81-90. DOI: 10.1016/j.jsg.2019.03.006. This is an author version of the article. For the final copy-edited version, please visit:

https://www.sciencedirect.com/science/article/pii/S0191814118303419

Keywords: Shear zones; Strain localisation; Anisotropy; Self-organisation, Strainrate distribution

\begin{abstract}
Localisation of ductile deformation in rocks is commonly found at all scales from crustal shear zones down to grain scale shear bands. Of the various mechanisms for localisation, mechanical anisotropy has received relatively little attention, especially in numerical modelling. Mechanical anisotropy can be due to dislocation creep of minerals (e.g. ice or mica) and/or layering in rocks (e.g. bedding, cleavage). We simulated simple-shear deformation of a locally anisotropic, single-phase power-law rheology material up to shear strain of five. Localisation of shear rate in narrow shear bands occurs, depending on the magnitude of anisotropy and the stress exponent. At high anisotropy values, strain-rate frequency distributions become approximately lognormal with heavy, exponential tails. Localisation due to anisotropy is scaleindependent and thus provides a single mechanism for a self-organised hierarchy of shear bands and zones from $\mathrm{mm}$ - to $\mathrm{km}$-scales. The numerical simulations are compared with the natural example of the Northern Shear Belt at Cap de Creus, NE Spain.
\end{abstract}




\section{Introduction}

Shear localisation is the concentration of deformation in part of the deforming material, usually in planar "shear zones" or, in the case of discrete planes, brittle faults. Here we only address localisation of ductile deformation (i.e. without loss of cohesion), which is a common phenomenon and develops at almost all scales in ductile rocks (Fig. 1), from small-scale shear bands to crustal-scale shear zones (e.g. Berthé et al., 1979; Hanmer and Passchier, 1991; Carreras, 2001; Carreras et al., 2010; Bak et al., 1975; Sørensen, 1983). Shear localisation is variable, from isolated shear zones to anastomosing networks (Arbaret et al., 2000; Mitra, 1979; Bell, 1981; Passchier, 1984; Gapais et al., 1987; Fusseis et al., 2006; Schrank et al., 2008; Ponce et al., 2013). The formation of such networks in rocks has been simulated experimentally (e.g. Herwegh and Handy, 1996; Bons and Jessell, 1999; GomezRivas and Griera, 2011; 2012; Gomez-Rivas et al., 2015) and numerically (e.g. Gardner et al., 2017; Meyer et al., 2017).

Despite decades of research, there is on going debate on the mechanisms of shear localisation. Strain-softening associated with dynamic recrystallisation can potentially lead to shear localisation (Rice 1987; Anand et al., 1987), for example by nucleation of new grains with relatively low dislocation densities (Tullis and Yund, 1985; Hirth and Tullis, 1992; Stipp et al., 2002; Fossen and Cavalcante, 2017), by grain boundary migration that lowers dislocation density (Shimizu, 2008; Fossen and Cavalcante, 2017), or by grain-size reduction in the case of grain-size sensitive creep (White et al., 1980; Tullis and Yund, 1985; Behrmann and Mainprice, 1987; Warren and Hirth, 2006). Questions remain whether grain-size reduction can actually lead to shear localisation (de Bresser et al., 1998, 2001; Platt and Behr, 2011). Localisation of strain can also occur in the strain-hardening regime (Hobbs et al., 1990). However, in each case the softening rate needs to overcome any hardening rate to initiate localisation (e.g. Estrin and Kubin, 1991).

Deformation by dislocation-creep mechanisms can soften the rock due to the formation of a crystal-preferred orientation (CPO) if deformation rotates slip planes into favourable orientations (Poirier, 1980; Mainprice et al., 1986; Ji et al., 2004; Passchier and Trouw, 2005; Warren et al., 2008; Oliot et al., 2014; Fossen and Cavalcante, 2017; Llorens et al., 2016a,b; 2017). This is a form of geometric weakening, in which the internal geometry of the material changes with strain. Geometric weakening also includes the development of a shape-preferred orientation (SPO), the re-orientation or redistribution of phases, e.g. alignment of planar minerals (e.g. micas), elongated grains or other components that make up a fabric (Jordan, 1988; Handy, 1990, Shea and Kronenberg, 1993; Johnson et al., 2004). Softening can further be induced by a change of composition, by introduction of a weak phase, such as melt (Brown and Solar, 1998; Rosenberg and Handy, 2000; Handy et al., 2001) or by reaction softening during metamorphism in which new and, possibly, weaker minerals grow (Poirier, 1980; Mainprice et al., 1986; Ji et al., 2004; Passchier and Trouw, 2005; Regenauer-Lieb et al., 2009; Warren et al., 2008; Oliot et al., 2014; Fossen and Cavalcante, 2017). Introduction of (aqueous) fluids can induce softening by water weakening, enhancing dynamic recrystallization (e.g. fluid-assisted grain boundary migration; Urai, 1983) or enabling dissolution-precipitation creep (Hirth and Tullis, 1992; Mancktelow and Pennacchioni, 2004; Menegon et al., 2008; Oliot et al., 2014; Finch et al., 2015). 

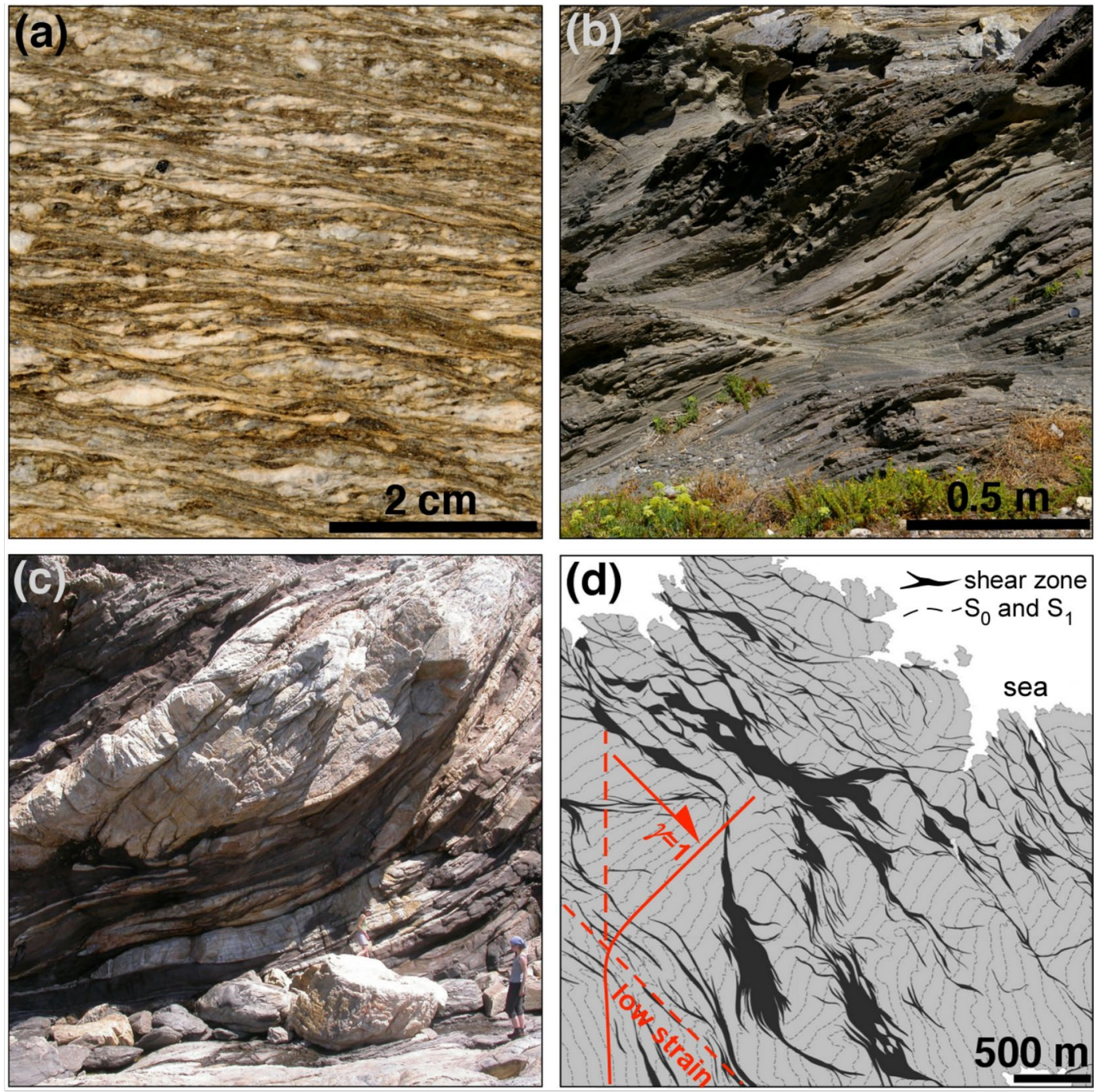

Fig.1. Shear localisation on all scales at Cap de Creus, Eastern Pyrenees, Spain (a) Shear bands in deformed granodiorite at the Roses lighthouse (Carreras et al. 2004). (b) Shear zone in meta-turbidites at Tudela (Druguet, 1997). (c) Large shear zone (note the person in the lower right for scale) at Punta dels Farallons (Druguet and Hutton, 1998). (d) Shear zones (black) in the Northern Cap de Creus shear belt forming an anastomosing pattern. Modified after Carreras (2001). Dashed red line shows the deflection of the bedding and bedding-parallel $\mathrm{S}_{1}$ cleavage by approximately NW-SE-directed dextral shearing.

Shear heating is an additional mechanism that can soften a deforming rock with a temperature-dependent rheology, leading to shear localisation (Hobbs and Ord, 1988; Thielmann and Kaus, 2012; Thielmann et al., 2015; Thielmann, 2017; Brun and Cobbold, 1980; Bercovici, 1993).

For shear localisation to occur, instabilities must develop that inhibit a homogeneous distribution of deformation. Such instabilities can result from the above-mentioned strain-softening mechanisms, but also from strain-hardening (Hobbs et al., 1990). In general, strain-softening processes are able to narrow shear zones (Ben-Zion and Sammis, 2003), whereas strain-hardening processes can widen them (Means, 1984; Hull, 1988; Fusseis et al., 2006; Schrank et al., 2008). Most of the above shear localisation mechanisms assume a localisation of ductile shear with progressive strain. However, the opposite has also been proposed: shear zone initiation on brittle fractures (the extreme end member of localisation) that 
subsequently widen into ductile shear zones (Segall and Simpson, 1986; Fusseis et al., 2006; Pennacchioni and Mancktelow, 2007; Goncalves et al., 2016).

Shear zones are often arranged in anastomosing networks (Ramsay and Allison, 1979; Bell, 1981; Hudleston, 1999), formed by linking of segments due to accumulated strain and displacement (Schrank et al., 2008; Fossen and Cavalcante, 2017). The Cap de Creus peninsula of the easternmost Pyrenees (Spain) provides an excellent example of such networks (Fig. 1d) (Druguet et al., 1997; Carreras, 2001; Carreras et al., 2004; Fusseis et al., 2006; Schrank et al., 2008). The shear zones developed in medium to high metamorphic-grade biotite schists under retrograde metamorphic conditions (Druguet et al., 1997, 1998). A progressive non-coaxial deformation regime is assumed to be responsible for their development (Carreras, 2001). The shear zones form a complex pattern, as they are linked in an anastomosing framework with self-similar properties (Carreras, 2001). In Cap de Creus one finds localisation structures and anisotropies from the grain scale to the scale of the entire, ca. $4 \mathrm{~km}$ wide, Northern Shear Belt (Schrank et al., 2008).

Many studies have addressed scale invariance in geological media (Gutenberg and Richter, 1956; Turcotte, 1990; Turcotte, 1992; Bonnet et al., 2001). Nonlinearity is an essential condition for self-similar (fractal) statistics, which supports the system to be highly dynamical (Turcotte, 1997). Even tectonic plates display fractal distributions up to the largest plates (Bird, 2003; Sornette and Pisarenko, 2003), which can be explained with a dynamical model of plates with creation, fragmentation and destruction acting on all scales (Sornette and Pisarenko, 2003). Shear zone networks often develop over several orders of magnitude (Sammis and Steacy, 1995; Hippertt, 1999; Carreras, 2001; Carreras et al., 2010). Tchalenko (1970) identified similarities between shear zones at different magnitudes (microscopic scale in shear box tests, intermediate scale in Riedel experiments, outcrop scale in earthquake faults), interpreting these in terms of mechanical properties of the material, the failure criterion and deformation kinematics. Fractal analysis of shear bands indicates that shear rate values are multifractal (Poliakov et al., 1994; Poliakov and Herrmann, 1994; Herrmann et al., 1995). Fractal distributions of shear bands that evolve spontaneously from a rather homogeneous strain distribution suggest the existence of some kind of self-organisation (Bak et al., 1987; Turcotte, 1992), where each shear band may be seen as a single internal "avalanche" on which the system releases stresses through larger displacements (Herrmann et al., 1995). In numerical simulations (e.g. Herrmann et al., 1995; Ran et al., 2018) shear bands develop without tuning of external control parameters, which is a necessary condition for selforganization (Bak et al., 1987).

Many properties are known to be highly anisotropic in rocks and materials. When a material deforms, anisotropy originates through the development of CPOs and/or SPOs (Mainprice and Nicolas, 1989; Passchier and Trouw, 2005), which can trigger the development of foliations, which in turn can result in internal instabilities. During deformation, anisotropic rocks develop internal structures whose geometry depends on the degree and type of anisotropy. Cobbold et al. (1971), for example, define the degree of anisotropy as the difference in the stress/strain moduli for shear or compression in a given direction. Other authors have defined it as the ratio between the viscosity under normal stress and viscosity under shear stress (e.g. Johnson and Fletcher, 1994; Treagus, 2003; Kocher et al., 2006; 2008). Griera et al. (2013), 
Llorens et al. (2016a,b, 2017) and Ran et al. (2018), as well as this paper define anisotropy $(A)$ as the ratio of the critical resolved shear stress between the strongest and weakest slip systems. With type of anisotropy we refer to intrinsic (e.g. Griera et al., 2013; Llorens et al., 2016a, 2016b, 2017 and Ran et al., 2018) versus composite anisotropy (e.g. Cobbold et al., 1971; Hudleston and Treagus, 2010; Dabrowski and Schmid, 2011; Griera et al., 2013; Gomez-Rivas et al., 2015). The lower crust develops a mechanical anisotropy as the result of intrinsic layering, which is enhanced by the anisotropy induced by stretching (Cosgrove, 1997). The shear zones at Cap de Creus (Fig. 1) could be a result of anisotropy-induced shear localisation, as these have been interpreted as resulting from inherited anisotropies such as meta-turbidite layering, the axial planar S1-foliation, and pegmatite bodies (Druguet et al., 1997; Carreras, 2001; Schrank et al., 2008; Ponce et al., 2013). Furthermore, the degree of anisotropy impacts on, for instance, the geometry of deformed single layers (Toimil and Griera, 2007; Kocher et al., 2008; Llorens et al., 2013a), the reactivation of fault and shear zones (Tommasi et al., 2009) and on shear zone formation over pre-existing fabrics (Michibayashi and Mainprice, 2004).

Although anisotropy has been recognised as an important factor in the formation of geological structures, relatively few numerical studies have included it (see discussion by Ran et al., 2018). Most distinct exceptions are models of folding in anisotropic media (Cobbold, 1976; Latham, 1979; Mühlhaus et al., 2002; Llorens et al., 2013a; $2013 \mathrm{~b}$ ), and the influence of anisotropy on rigid object behaviour (Fletcher, 2004; Fletcher, 2009; Griera et al., 2011, 2013). In most numerical studies anisotropy is implemented in the model by introducing a layering of typically alternating hard and soft isotropic phases, creating a specimen with a "composite anisotropy" (see Hudleston and Treagus (2010), and references therein; Dabrowski and Schmid, 2011). Few studies have utilized an intrinsic anisotropy, where the rheology of the material itself is anisotropic (e.g. Lebensohn, 2001; Griera et al., 2013). Here we present a series of numerical simulations to investigate strain (rate) localisation due to mechanical anisotropy. We aim to quantify the amount of localisation, which can emerge in a single-phase material as a function of degree of anisotropy. We use the same approach to model an intrinsically anisotropic material as in Griera et al. (2013), with the parameter defining anisotropy comparable to the ratio between normal and shear viscosity, as defined in Kocher et al. (2006; 2008). The anisotropy parameter $A$ is therefore equivalent to the viscous anisotropy (see appendix). The simulations aim to quantify the amount of localisation (localisation factor $L$; eq. 4 ) as a function of anisotropy and allow making predictions on the expected volume fraction of material that experiences high strain, recognisable as shear zones in deforming rocks and ice sheets.

\section{Methods}

In order to determine how mechanical anisotropy affects the amount of localisation (localisation factor $L$; eq. 4), we simulate the deformation of a material with an intrinsic mechanical anisotropy arising from different slip resistance of individual slip systems within a single crystallite or grain. The crystallographic orientation can evolve with progressive deformation and vary locally within the model. 


\subsection{The VPFFT-ELLE modelling platform}

We use the viscoplastic full-field formulation (VPFFT) based on the Fast Fourier Transform coupled with the modelling platform ELLE (Lebensohn, 2001; Lebensohn et al., 2008; Griera et al., 2011, 2013; Llorens et al., 2016a; Steinbach et al., 2016) to calculate the stress and strain rate distribution during progressive simple shear. ELLE is an open-source modelling platform (http://www.elle.ws; Jessell et al., 2001; Bons et al., 2008) and aims to provide a generalized framework for the numerical simulation of the evolution of microstructures during deformation and metamorphism. The VPFFT+ELLE code has recently been used to simulate recrystallisation in deforming ice and halite (Llorens et al., 2016a,b; Llorens et al. 2017; Gomez-Rivas et al., 2017; Steinbach, 2016, 2017), viscoplastic deformation of hard inclusions (Griera et al., 2011, 2013; Ran et al., 2018) and folding in anisotropic materials (Bons et al., 2016; Jansen et al., 2016; Ran et al., 2018).

\subsection{Definition of the model}

Our 2D models consist of unconnected nodes (unodes), which provide a highresolution regular grid for storing physical properties such as crystal orientation (defined by three Euler angles), stresses and strain rates. The unodes effectively represent crystallites or single grains with a constant internal crystal orientation. We use a second, non-regular, layer of unodes as passive markers to visualise the finite deformation field, consisting of initially parallel lines that are oriented perpendicular to the horizontal shear plane.

\subsection{Viscoplastic deformation using the full-field approach}

The VPFFT approach calculates the strain rate and stress fields that satisfy the constitutive relation at a local level, under the constraints of strain compatibility and stress equilibrium (see Lebensohn (2001), Lebensohn et al. (2008; 2009) and Montagnat et al. (2014) for a more detailed description of the theoretical framework and numerical algorithm, and Griera et al. (2013) and Llorens et al. (2016a,b) for the coupling with ELLE). The "full field" designation indicates that the approach explicitly resolves velocity and stress fields with a resolution that is defined by the size, $S \mathrm{x} S$, of the unode or Fourier grid.

We simulate the anisotropic behaviour using a nonlinear viscous rate-dependent approach, where deformation is assumed to be accommodated by dislocation glide only, taking into account the different available slip systems (Lebensohn, 2001; Lebensohn et al., 2008, 2009; Montagnat et al., 2014). The constitutive equation for the relation between strain rate $\dot{\varepsilon}_{i j}(\boldsymbol{x})$ and the deviatoric stress $\sigma^{\prime}(\boldsymbol{x})$ at position $\boldsymbol{x}$ of the Fourier grid is given by

$$
\begin{aligned}
\dot{\varepsilon}_{i j}(\boldsymbol{x}) & =\sum_{s=1}^{N_{s}} m_{i j}^{s}(\boldsymbol{x}) \dot{\gamma}^{\prime}(\boldsymbol{x}) \\
& =\dot{\gamma}_{0} \sum_{s=1}^{N_{s}} m_{i j}^{s}(\boldsymbol{x})\left|\frac{m_{i j}^{s}(\boldsymbol{x}): \sigma_{i j}{ }^{\prime}(\boldsymbol{x})}{\boldsymbol{\tau}_{0}^{s}(\boldsymbol{x})}\right|^{n} \operatorname{sgn}\left\{m_{i j}^{s}(\boldsymbol{x}): \sigma_{i j}{ }^{\prime}(\boldsymbol{x})\right\}
\end{aligned}
$$

where the sum runs over all $\left(N_{s}\right)$ slip systems $(s)$ in the crystal, $m^{s}$ is the symmetric Schmid tensor, $\tau_{0}{ }^{s}$ is the critical resolved shear stress or slip system dependent rate 
factor, $\dot{\gamma}^{s}$ is the shear strain rate, $\dot{\gamma}_{0}$ is the reference strain rate and $n$ is the stress exponent. The material is thus rigid (i.e. elasticity is neglected) - viscoplastic (i.e. anisotropic non-linear (when $n>1$ ), without a true yield stress). The anisotropy is defined by $\tau_{0}{ }^{s}$ of each slip system and the crystal system and its symmetry. We use the same hexagonal crystal symmetry of ice $1 \mathrm{~h}$ as in Llorens et al. (2016a, 2016b, 2017), Griera et al. (2011; 2013) and Ran et al. (2018) for our single-phase material, in which deformation is allowed to be accommodated by glide along the basal plane and non-basal, pyramidal and prismatic planes (Griera et al., 2013). The degree of anisotropy, $A$, is defined as the ratio between the critical resolved shear stresses of the basal and all other, non-basal slip systems:

$$
A=\frac{\tau^{(\text {non-basal })}}{\tau^{(\text {basal })}}
$$

with $\tau^{\text {(non-basal) }}$ equal to $A$ and $\tau^{\text {(basal) }}$ always one. This definition is equivalent to classical approaches of mechanical anisotropy as the ratio between normal and shear viscosities (see appendix). Each deformation step, the VPFFT code calculates the stress and velocity field for the whole model. Velocities are applied for a shear-strain increment of $\Delta \gamma=0.02$. Since the VPFFT code requires a rectangular grid of unodes, the ELLE-code subsequently maps the translated material states of the shifted unodes (here the Euler angles) back on the original square grid. This routine employs the feature that the data structures of both the VPFFT and ELLE codes are fully wrapping. Therefore, a material point that moves across the right boundary enters the model on the left again. This way, the model can be represented by a square box at all times, which allows the modelling up to large strains without changing the outer shape of the model.

\subsection{Experimental setup}

We use a square model with $128 \times 128,256 \times 256$ and $512 \times 512(S=128,256,512)$ unodes, respectively. Each individual simulation considers a single material that is defined by its anisotropy, with $A \geq 1$, and $\tau^{\text {basal }}$ is always set to unity. Each unode in the model is initially assigned a random crystal orientation. We simulate the deformation of the material in dextral simple shear up to a shear strain of five in strain increments of $\Delta \gamma=0.02$. Boundary conditions are such that the velocities at the boundaries are on average simple shear. Three series of simulations are presented here (Table 1): In series I we varied the anisotropy parameter $A$. With series II we investigate the impact of different model sizes $S$ on strain rate localisation. In series III we varied $n$ from one to four, and set $A$ such that the effective viscosity ratio for non-basal and basal slip is 4096.

Table 1: Simulation parameters

\begin{tabular}{llll}
\hline Series name & Anisotropy $(A)$ & Stress exponent $(n)$ & Size $(S x S)$ \\
\hline Series I & $1,4,16,64$ & 3 & 512 \\
Series II & 16 & 3 & $128,256,512$ \\
Series III & $8,16,64,4096$ & $1,2,3,4$ & 256 \\
\hline
\end{tabular}




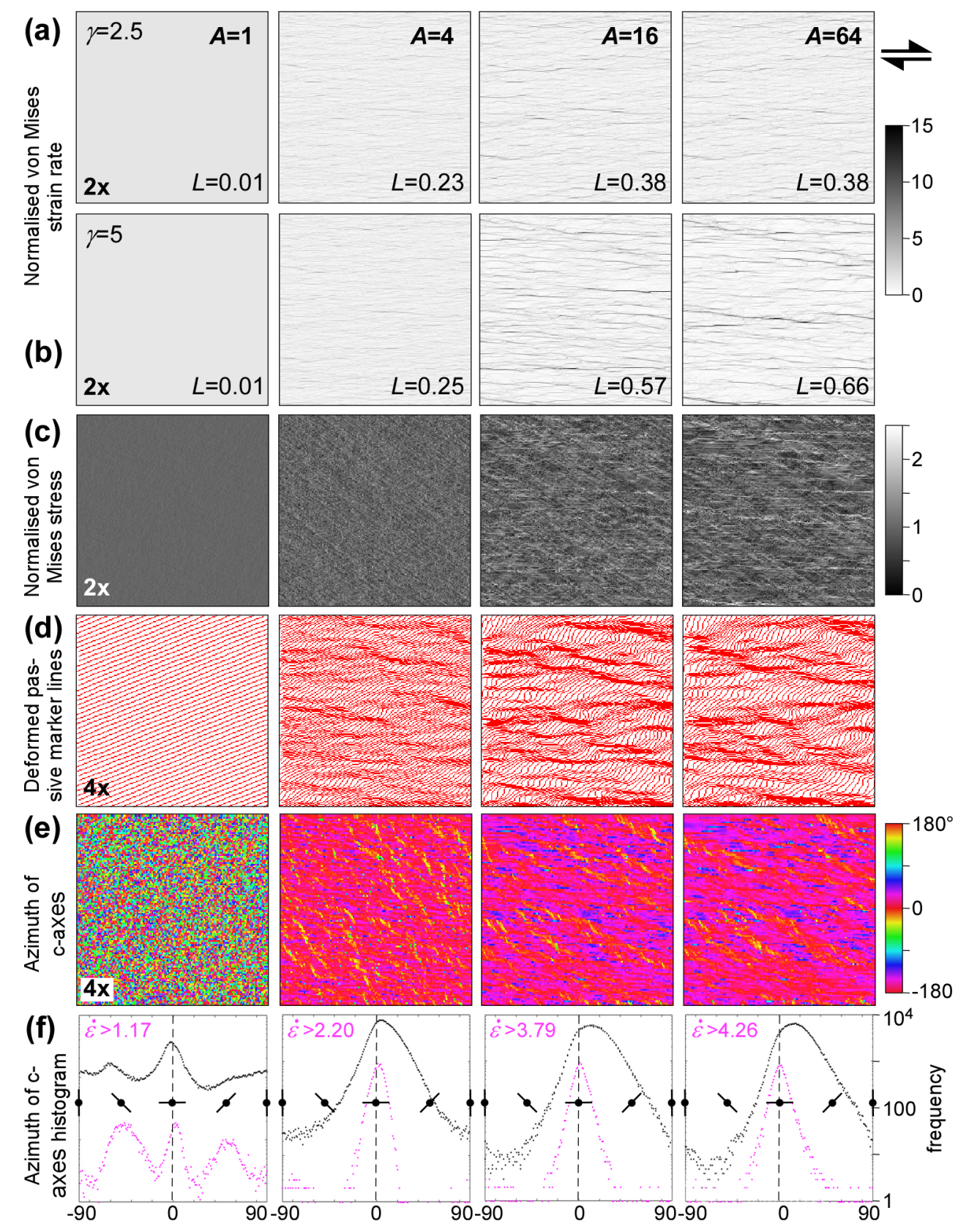

Fig. 2. VPFFT-ELLE simulations (series I) of dextral simple shear up to a shear strain of $\gamma=5$. The degree of mechanical anisotropy $(A)$ increases from 1 (quasi-isotropic) to 64 (highly anisotropic). Evolution of Von Mises strain-rate field, normalized to the bulk value, at a shear strain of (a) $\gamma=2.5$ and (b) $\gamma=5$. In both (a) and (b) images have been enlarged $2 \mathrm{x}$ only showing the upper left quarter of the model. In the isotropic case $(A=1)$ no strain localisation occurs. In all anisotropic cases sub-horizontal shear bands develop. (c) Von Mises stress field at a shear strain rate of $\gamma=5$. Highest stress values are within high strain zones. Stripes in the images are attributed to imperfect solutions for the stress field in the iterative VPFFT code. (d) Passive marker lines at a shear strain of $\gamma=5$ to illustrate the distribution of finite-strain. Images have been enlarged 4x, only showing the upper left part of the model box. (e) Orientation of c-axes azimuths (Euler $\phi$, or azimuth angle relative to the vertical) at $\gamma=5$. The images have been enlarged 4x, only showing the upper left part of the model box. (f) Frequency distributions of c-axes azimuths. When separating the high-strain values from the entire model (highest $5 \%$ of normalised Von Mises strain rate values) and analyse c-axis orientation within it at $\gamma=5$ it becomes apparent that c-axis azimuths are close to perpendicular to the shear plane, but oriented with a broad maximum of $80^{\circ}$ to the shear plane in the entire model. A linear bin width of $1.8^{\circ}$ has been used to generate the frequency distributions. 


\subsection{Data visualisation}

Stress and strain rate distributions are visualised by mapping the normalised Von Mises strain rates $\left(\dot{\varepsilon}_{v m}\right)$ and Von Mises stresses $\left(\sigma_{v m}\right)$ (Fig. 2a-c), which are defined in terms of the second invariants of the symmetric strain rate and deviatoric stress tensors respectively:

$$
\dot{\varepsilon}_{V M}=\sqrt{\frac{2}{3} \dot{\varepsilon}_{i j} \dot{\varepsilon}_{i j}} \text { and } \sigma_{\mathrm{VM}}=\sqrt{\frac{3}{2} \sigma^{\prime}{ }_{\mathrm{ij}} \sigma_{\mathrm{ij}}^{\prime}} \text {. }
$$

To visualise the finite-strain field, we use passive markers (Fig. 2d). The passive marker lines are initially defined as vertical lines and track the position of unodes, treated as passive material markers. The bulk stress is calculated by averaging all stresses of individual unodes. Crystal orientations are visualised by mapping the Euler- $\phi$ angles, i.e. the azimuth of the c-axis relative to the vertical axis (Fig. 2e). Frequency distributions of Euler- $\phi$ angles show the preferred orientation of c-axis (Fig. 2f).

\subsection{Strain Localisation}

We quantify the strain-rate localisation $(L)$ in our model with a localisation factor defined by Sornette et al. (1993) and Davy et al. (1995), and modified by GomezRivas (2008), Steinbach et al., (2016) and Llorens et al. (2017):

$$
L=1-\frac{\left(\sum_{n_{i}}^{n_{t}} \dot{\varepsilon}_{V M}\right)^{2}}{n_{i} \sum_{n_{i}}^{n_{i}}\left(\dot{\varepsilon}_{V M}\right)^{2}},
$$

where $n_{t}$ denotes the total number of unodes. The strain localisation factor ranges from 0 to 1 , where 0 means homogeneous deformation and 1 maximum localisation, where all strain is accommodated by a single unode.

\section{Results}

Results of Series I show that distinct strain and strain-rate localisation occurs in all cases where $A>1$ (Fig. 2a-c). Although the material with $A=1$ is strictly speaking not isotropic, it behaves as an effectively isotropic material (Griera et al., 2011). Stress and strain rates show very little variation $(L<0.01)$ and the passive marker lines remain straight as before deformation (Fig. 2d). However, Euler- $\phi$ distributions indicate a maximum in c-axes perpendicular to the shear plane (Fig. 2e,f).

For $A>1$, the normalised Von Mises strain-rate $\left(\dot{\varepsilon}_{V M}\right)$ field becomes increasingly heterogeneous with progressive strain (Fig. 2a,b). High strain rate bands oriented at a low angle to the horizontal shear plane are clearly visible (Fig. 2a,b). Localisation of finite strain can be identified in the passive marker lines (Fig. 2d), which shows distinct shear bands for $A=16$ and $A=64$, and less localisation for $A=4$. This reveals that the heterogeneity in strain rate is not averaged out with progressive strain. For all anisotropic cases $(A>1)$, c-axes become preferentially oriented with a broad maximum at about $80^{\circ}$ to the shear plane (Fig. 2e,f). Within the high strain-rate zones (highest $5 \%$ of strain-rate values) the c-axes preferred orientation is stronger with the azimuths of c-axes closer to perpendicular to the shear plane (Fig. 2f). Material within the shear zones thus has its basal plane well-oriented for the applied bulk simple shear. The 
strength of the c-axes preferred orientation within the shear zones decreases slightly from $A=4$ to $A=64$.

The frequency distribution of strain rates (Fig. 3a,b) for an effectively isotropic material $(A=1)$ at a shear strain of $\gamma=5$ is approximately normal. For $A>1$, the frequency distributions deviate from a normal distribution and shift towards lognormal distributions. Frequency distributions for $A=16$ and $A=64$ are almost identical up to a normalised strain rate of about five. However, the frequency distributions become heavy tailed and are therefore not exactly log-normal (Fig. 3b). High strain rate values become overrepresented and have values that are up to ca. 20 times higher

(a)
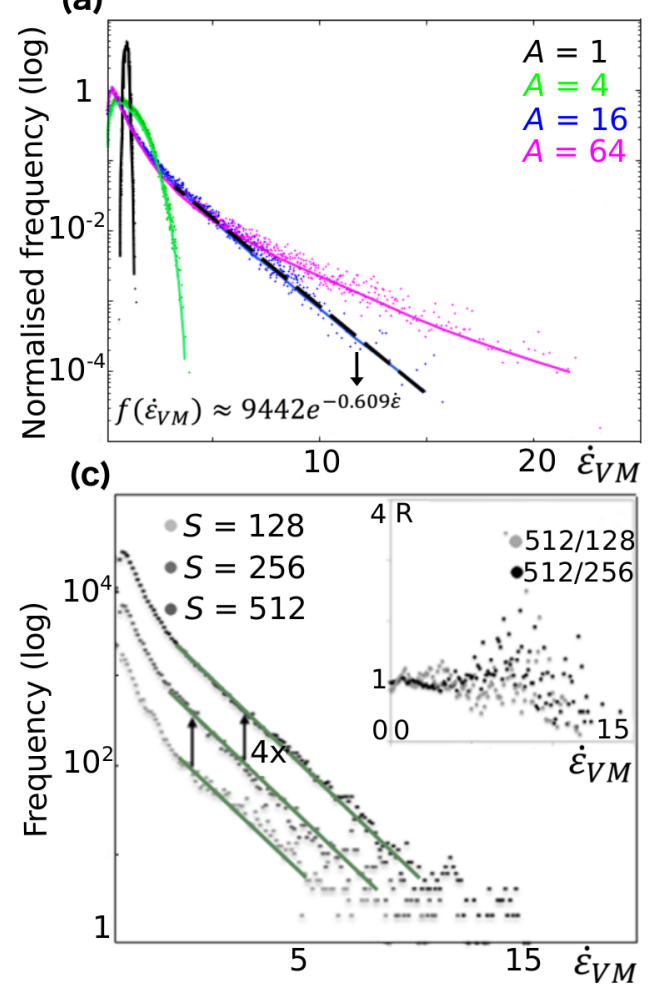

(b)
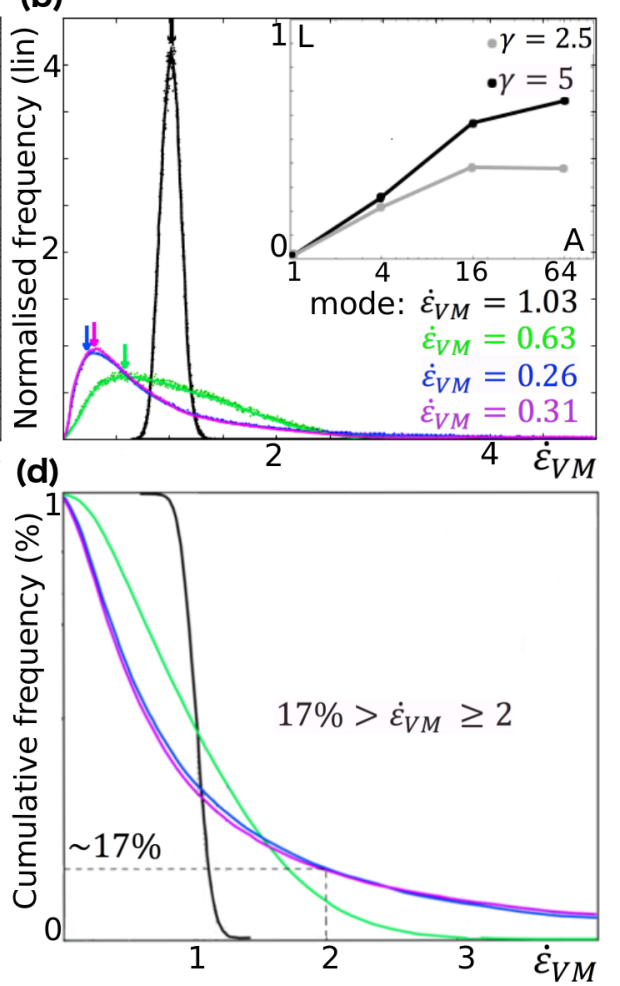

Fig. 3. Frequency distributions of normalised Von Mises strain rates at a shear strain rate of $\gamma=5$. Normalised frequency distributions of normalised Von Mises strain rate in (a) log-linear and (b) linear scaling, for anisotropy parameters of $A=1,4,16$ and 64 (series I). Frequency distributions have been processed with linear bin widths of 0.002 (for $A=1), 0.008(A=4), 0.031(A=16)$ and $0.048(A=64)$. For the isotropic material $(A=1)$ the frequency distribution is approximately normal with the mode slightly above one. Modes are indicates by arrows. Higher anisotropy leads to data peaks which are below the mean, whereas the high strain rate values develop a heavy tail, which becomes more pronounced with increasing $A$. Inset in (b) shows the localisation factor $L$ plotted against $A$ (for $\gamma=2.5$ and $\gamma=5$ ), illustrating an increase of localisation from $A=1$ to $A=16$, though the intensity of localisation increases very little from $A=16$ to $A=64$. (c) Frequency distribution for different model sizes (Series II; 128x128, $256 \times 256,512 \times 512$ unodes). To be able to compare the different data sets, a linear bin size of 0.1 has been used to calculate the frequency distributions. As one can see, for a system size of 512 by 512 unodes the frequency of Von Mises strain rate values appears four times more often than for a systems with a size of 256 by 256 unodes, and 16 times more often than for a system with 128 by 128 unodes. Inset in (c) shows the ratio $R$, which compares frequency distributions of Von Mises strain rate for different model sizes. (d) Cumulative frequency distribution of the same data set as in (a) and (b).

than the mean for $A=64$ (Fig. 3a,b). Therefore, a material with a higher degree of anisotropy reaches significantly higher strain-rate values due to strain localisation. As a result, a major part of the material deforms at a significantly lower rate than the mean strain rate, as can be seen by the leftward shift of the frequency peak (Fig. 3a,b). 
The inset in figure $3 \mathrm{~b}$ shows the localisation factor $(L)$ plotted against the anisotropy parameter $(A)$, and illustrates that localisation increases from $A=1$ to $A=16$, although localisation increases very little from $A=16$ to $A=64$.

When comparing the frequency distributions of Von Mises strain rate for different model sizes $(S)$ in Series II, we observe that the shape of the $\dot{\varepsilon}_{V M}$ frequency distribution is largely independent of $S$ (Fig. 3c). For example, the probability to reach a particular strain rate $f\left(\dot{\varepsilon}_{V M}\right)$, for a $512 \times 512$ model is four times higher than that for a simulation with $256 \times 256$ unodes, and 16 times higher than that for a simulation with $128 \times 128$ unodes. The ratio $R$, defined as

$$
R=\frac{f_{\left(\varepsilon_{V: 1}, S_{1}\right)} / f_{\left(\dot{\varepsilon}_{\text {VAt }}, S_{2}\right)}}{\left(S_{1} / S_{2}\right)^{2}}
$$

is approximately unity (inset in Fig. 3c). The highest strain rates that are achieved in a simulation do, however, depend on $S$. The frequency of $\dot{\varepsilon}_{V M}=15$ is about one per $512 \times 512$ unodes (i.e. $=262,144$ unodes) for $A=16$ and $\gamma=5$. This means that the chance that one unode with $\dot{\varepsilon}_{V M}=15$ occurs in a $128 \times 128$ unode model is only $1 / 16$ or about $6 \%$.

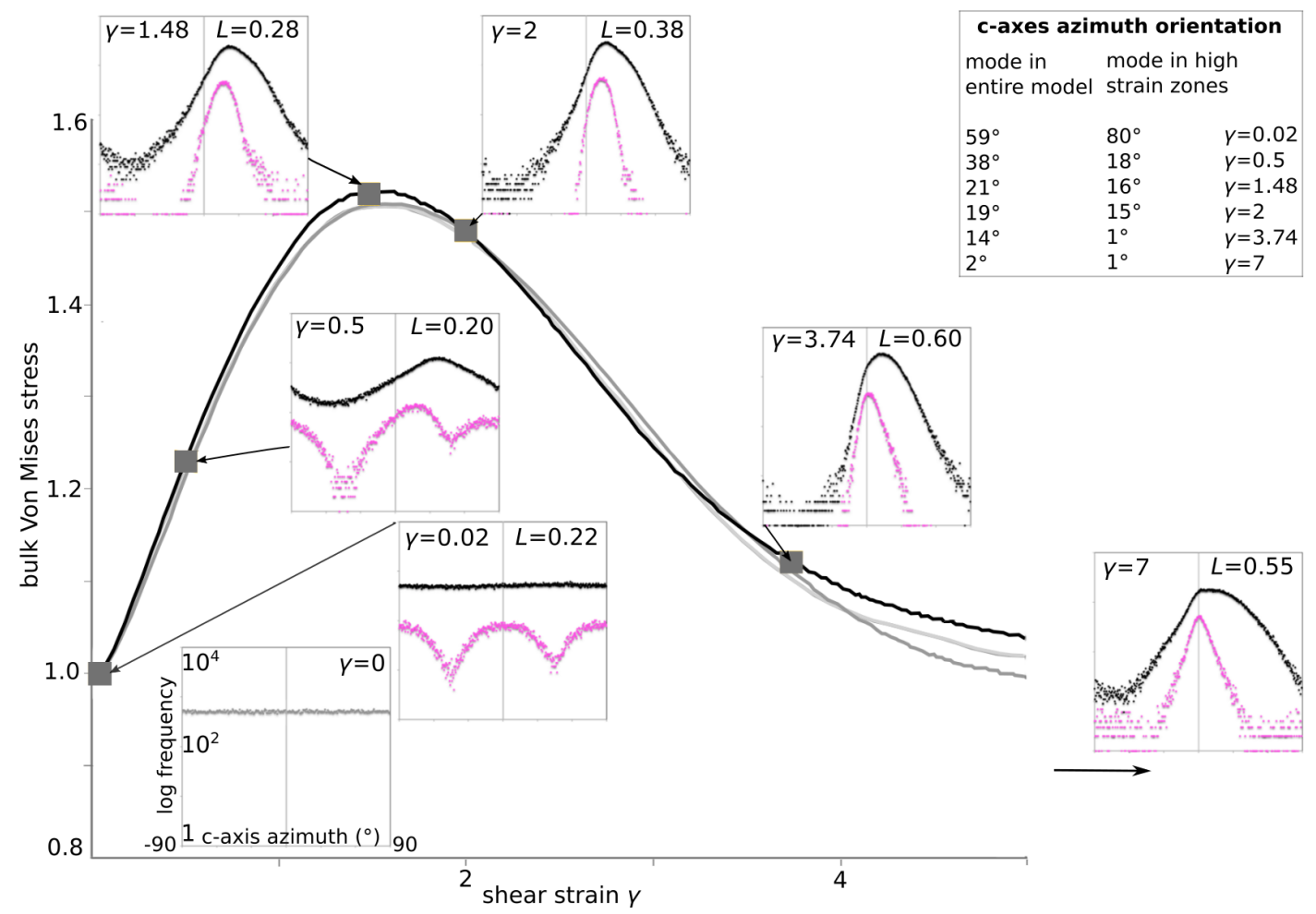

Fig. 4. Plot of bulk Von Mises stress ( $\sigma_{V M}$ normalised to $\sigma_{V M}$ at $\gamma=0$ ) versus shear strain for $A=16$ and three different model resolutions ( $S=128$ (light grey), $S=256$ (grey), $S=512$ (black)). The curves show initial hardening, followed by softening. The curves differ only marginally and not consistently with resolution. The variation in $\sigma_{\mathrm{VM}}$ at a certain strain rate is therefore not due to resolution, but stochastic variations between the simulations. C-axes azimuth frequency distributions for both unodes in the entire model box (black) and in the regions with 10\% highest strain rate (magenta) for selected points on the stress curve are shown in square boxes. Grey curve shows the initial c-axes azimuth distribution before deformation and contains data labelling for all boxes. Corresponding modes for selected points on the bulk Von Mises stress curve are shown in the box. 
Figure 4 shows the evolution of the bulk von Mises stress $\left(\sigma_{V M}\right)$ versus shear strain $(\gamma)$ for $A=16$ and three model sizes $(S=128, S=256, S=512)$. At the beginning the bulk stress increases, resulting in strain-hardening. During this stage c-axes start to align perpendicular to the shear plane. Already after a shear strain of $\gamma=0.02$ some of the unodes with $10 \%$ highest strain rates align at $90^{\circ}$ to shear plane (Fig. $4 ; \gamma=0.02$ )). After a shear strain of $\gamma=1.48$ the stress reaches the highest value and softening effects caused by the evolving CPO become stronger than hardening effects. At $\gamma=1.48$ most c-axes align ca. $69^{\circ}$ to the shear plane, whereas unodes with the highest strain rate values align ca. $74^{\circ}$ to the shear plane. After this stage the overall shape of the frequency distribution does not change much anymore, but becomes more pronounced. After reaching the stress peak localisation of deformation becomes stronger until reaching steady state. In steady-state c-axes in both the entire model and in the high strain zones all align approximately perpendicular to the shear plane. Localisation of strain rates is most distinct before reaching steady state (Fig. 4; $\gamma=3.74, L=0.60)$.

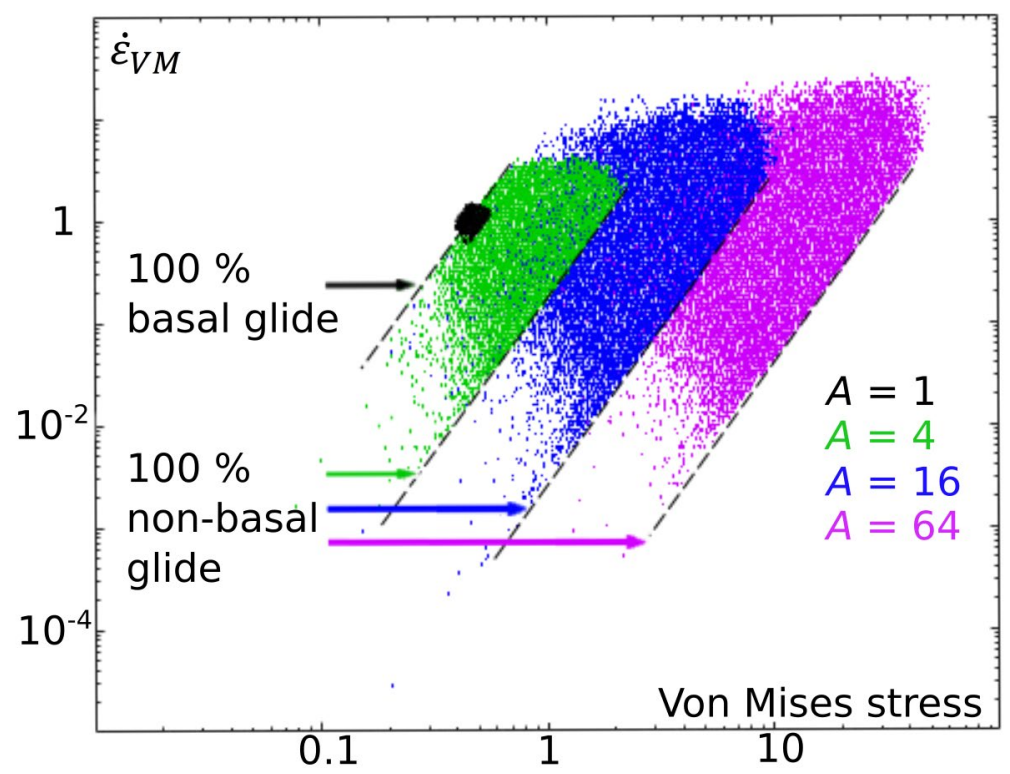

Fig. 5. Normalised Von Mises strain rate (normalised to bulk value) plotted against Von Mises stress at a shear strain rate of $\gamma=5$ for series I. Data plot in the form of a cloud, that spreads with increasing $A$. The bottom right side of each cloud plots as straight line with a slope of $n=3$. For $A=4$ the top left bound is a straight line as well. Points on the upper straight line are those with $100 \%$ basal glide, points on the lower bound are those with $100 \%$ non-basal glide. Since basal glide is set to unity for all cases, the bound for basal glide is the same for all $A$. Non-basal glide is set to 1, 4, 16 and 64 , resulting in a rightward shift of the lower bound. For $A=16$ and $A=64$ the upper left $100 \%$ basal glide is not reached. This can be explained by the fact that $100 \%$ basal glide is effectively an extremely soft unode, which, however, cannot deform freely, since it is constrained by its surroundings.

Plots of Von Mises stresses $\left(\sigma_{V M}\right)$ against normalised Von Mises strain rates $\left(\dot{\varepsilon}_{V M}\right)$ (for each unode, at $\gamma=5$ ) show a large scatter that increases with $A$ (Fig. 5). This means that both $\dot{\varepsilon}_{V M}$ (Fig. 3) and $\sigma_{V M}$ values become increasingly variable with increasing $A$. The scatter for each simulation has a lower bound, with an exponent $n=3$, that is defined by $\tau^{\text {(non-basal) }}$. Material points on this bound deform by non-basal glide. The upper bound is defined by $\tau^{\text {(basal) }}$ and material points that plot here deform by basal glide. With increasing $A$, the cloud moves to the right, because $\tau^{\text {(basal })}$ is always one, 
while $\tau^{\text {(non-basal })}$ corresponds to $A$. One also sees that fewer points reach the upper basal-glide-only bound with increasing $A$. Figure 5 shows that $\dot{\varepsilon}_{V M}$ and $\sigma_{V M}$ do correlate, but rather poorly. High- $\sigma_{V M}$ zones are visible in the $\sigma_{V M}$ distribution at high $A$ (Fig. 2c) and correlate to some extent with high $\dot{\varepsilon}_{V M}$ zones.

Results of Series III (Fig. 6) show distinct strain localisation for $n>1$ at $\gamma=5$ (Fig. 6a). The localisation factor increases with $n$, from $L=0.22$ for $n=1$ to $L=0.56$ for $n=4$, with only minor increase from $n=3$ to $n=4$ (Fig. 6a). The plot of Von Mises stresses $(\sigma V M)$ against normalised Von Mises strain rates $\left(\dot{\varepsilon}_{V M}\right)$ (Fig. 6) (for each unode, at $\gamma=5$ ) show largest scatter for runs with $n=3$ and $n=4$. With decreasing $n$ and increasing $A$ the scatter becomes less wide in the direction of strain rate, but reaches higher stress values (Fig. 6b). The non-basal bound is reached in all cases, but the basal bound never. When comparing normalised frequency distributions of normalised Von Mises strain rate for Series III (Fig. 6c), we observe that the mode shifts to the left for higher $n$. For $n=1$ and $A=4096$ the frequency plots as a shifted log-normal distribution. For $n=2$ to $n=4$ the frequency distribution plots approximately exponential, with a slightly higher tendency to evolve a heavy tail for higher $n$ values.

\section{Discussion}

The simulations indicate that mechanical anisotropy leads to distinct strain and strain-rate localisation into networks of sub-parallel shear bands, with the intensity depending on the degree of anisotropy and the stress exponent. Frequency distributions of Von Mises strain rates show heavy tails for high $A$, with an approximately exponential decrease in frequency of high $\dot{\varepsilon}_{V M}$ values (Fig. 3). These distributions emphasise the continuous nature of the $\dot{\varepsilon}_{V M}$ distributions, only cut off by the model resolution. Although a visual inspection of strain-rate and finite strain distributions (Fig. 1,2) suggests the presence of distinct shear zones or bands, the results indicate there is actually no sharp distinction between low and high strain (rate), but, instead, a continuum.

The bulk stress-strain curve (Fig. 4) is characterized by an initial strain-hardening stage followed by strain-softening. In all anisotropic cases the initially random oriented c-axes rotate perpendicular to the shear plane during strain-hardening, with the points with highest strain rates rotating fastest (Fig. 4). During deformation the difference between the peaks of c-axes in high strain zones and of all c-axes in the model becomes smaller, coherent with ice experimental results shown in Qi et al. (2019). At the peak bulk Von Mises stress softening starts to become stronger, resulting in stronger localisation of strain rates. This is a form of geometrical softening (e.g. Poirier, 1980; Estrin and Kubin, 1991). Figure 4 indicates that strainsoftening alone is not a sufficient condition for localisation and the softening rate must become such that it overcomes any hardening rate (Estrin and Kubin, 1991). The strain-hardening is not caused by any hardening law, but due to the development of the CPO (Llorens et al., 2016a). As in Takeda and Griera (2006), Dabrowski et al. (2012) and Llorens et al. (2016a) the development of the anisotropy (intrinsic or composite) does not directly lead to strain-softening, as it is preceded by a strainhardening stage. 


\section{(a) Normalised von Mises strain rate}
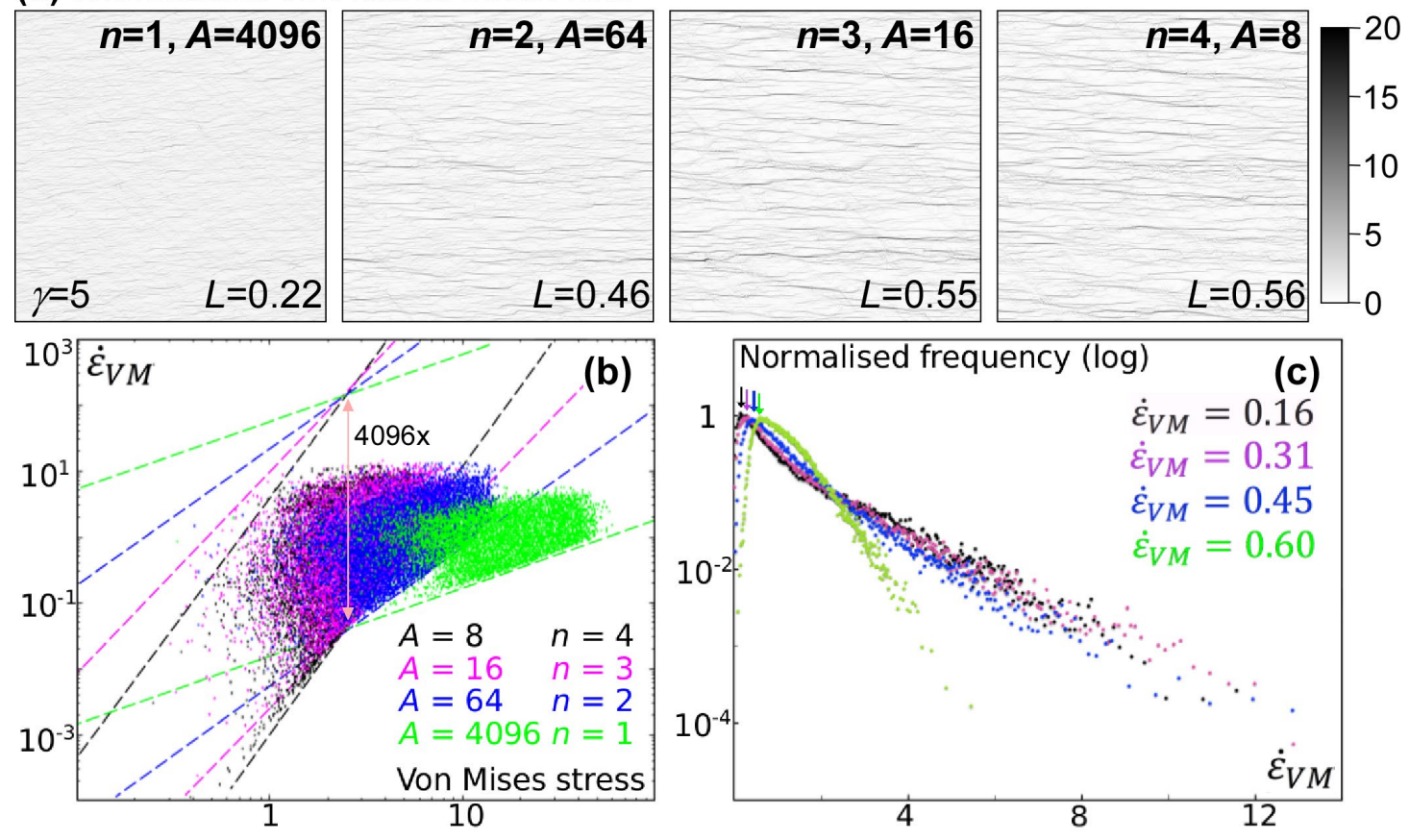

Fig. 6. Results for series III (a) Distribution of Von Mises shear strain rates, normalized to the bulk value, at a shear strain of $\gamma=5$. For $n=1$ and $A=4096$ only minor localisation is visible. For $n>1$ and A $<4096$ the localisation factor increases with increasing $n$ and decreasing $A$, with most strain localisation for $n=4$ and $A=8$, with only a minor difference to $n=3$. (b) Von Mises strain rate (normalised to bulk value) plotted against Von Mises stress at a shear strain rate of $\gamma=5$. The bottom right side of each cloud plots as straight line in $\log -\log$ with a slope of $n$ is 1 to 4 , where the dashed lines indicate the stress exponents of $n=1$ to 4 in corresponding colours respectively. The upper bound is a straight line with the same slope, but is never reached in any of the simulations. The pink arrow indicates maximum range of possibly reachable Von Mises strain rate values, which is always $\mathrm{A}^{n}=4096$. (c) Normalised frequency distribution of normalised Von Mises strain rates at a shear strain rate of $\gamma=5$ in a log-linear plot. Arrows indicate mode of normalised Von Mises strain rate for different configurations, which shift to the left with increasing $n$ and decreasing $A$. For $n=1$ the frequencies have a shifted log-normal distribution. For $n=2$ to 4 the frequency distribution are approximately exponential, with a slightly higher tendency for a heavy tail at higher $n$ values. Normalised frequency distributions have been calculated with linear bins of 0.022 for $n=1,0.052$ for $n=2,0.056$ for $n=3$ and 0.046 for $\mathrm{n}=4$.

Llorens et al. (2017) used the same VPFFT+ELLE approach as in this study to simulate the deformation of ice. Aice is assumed to range between 60 and 100 for $n=3$ for basal slip system and $n=2$ for non-basal slip systems (Duval et al., 1983), but Llorens et al used $A_{\text {ice }}=20$ to speed up calculation time and $n=3$ for all slip systems. This appears permissible if determining the amount of localisation is not the main aim of the study, as our $A=16$ and $A=64$ results are quite similar. In our simulations, each unode can be regarded as representing a single grain with a single, homogeneous crystal orientation. Llorens et al. (2017) modelled grains composed of many unodes and incorporated dynamic recrystallisation. Yet, they also observed strong strain (rate) localisation. When comparing our results with those from Llorens et al. (2017) one observes that although we use no dynamic recrystallisation we get a localisation factor $(L \approx 0.38$ at $\gamma=2.5)$ that is similar to that of a polycrystalline material with minor recrystallisation. Our results (without recrystallisation and substructures within grains) would thus overestimate the amount of localisation (for a given $A$ ) in very pure ductily deforming materials that flow at slow rates (such as ice sheets). When, however, the contribution of recrystallisation is suppressed by high strain rates, 
impurities and/or the presence of multiple minerals (as is common in rocks), our simulations may give an indication of the amount of strain localisation that can be expected.

Heavy tailed frequency distributions are often assumed to indicate underlying selfsimilar (fractal) processes (e.g. Bons and van Milligen, 2001; Brunetti, 2009). Such distributions are usually approximately log-normal, with or without a power-law or exponential tail, depending on small changes in model assumptions (Hähner, 1996; Hähner et al., 1998; Mandelbrot, 1997; Mandelbrot, 2001; Mitzenmacher, 2004). The frequency distributions of strain rates (Fig. 3) as well as their spatial distributions (Fig. 2a, b) support the notion that strain (rate) localisation is self-similar. Between the most conspicuous shear zones, one can discern less distinct shear zones as well. The same was proposed for the pattern of shear localisation at Cap de Creus (Fig. 1, and Carreras, 2001). Shear localisation happens on all scales, making $\mathrm{cm}$-scale shear bands (Fig. 2d) small versions of the larger shear zones that contain them (e.g. Hippertt, 1999; Carreras, 2001).

The scale-independence of the strain rate distributions (as a result of anisotropy; Fig. 3c) has a major advantage that the models can be used for predictions on scales well beyond the limited scales of our computer models (due to limited computing time and memory capacity). If we assume that $A=16$ is representative of the schists at Cap de Creus that have a strong layer-parallel foliation, defined by aligned biotite (Druguet et al., 1997; Carreras, 2001). 17\% of the area shown in Fig. 1d is mapped as "shear zone" by Carreras et al. (2004), i.e. material with distinctly higher strain than the rest of the outcrops. The cumulative strain-rate distribution indicates that, at $A \geq 16$, $17 \%$ of the material has a strain rate of $\geq 2$ times the average (Fig. $3 \mathrm{~d}$ ), which itself is about three to four times the mode (Fig. 3b). Deformation in the area shown in Fig. 1d is approximately NW-SE directed dextral simple shear with a transpressive component (Druguet et al., 1997; Carreras, 2001; Druguet, 2001; Bons et al., 2004). The general trend of the subvertical bedding and parallel $S_{1}$ foliation rotates about $45^{\circ}$ relative to the low-strain area in the SW-corner. Shear strain in the most abundant $(\approx 83 \%)$, non-shear-zone areas (i.e. lozenges) is thus in the order of unity. Assuming that this $\gamma \approx 1$ is the mode, the $17 \%$ of the area that is mapped as shear zone would then have a shear strain of at least six to eight. Such shear strains would indeed warrant mapping them as shear zone. The average shear strain would be about three to four. The aim of this comparison with Cap de Creus here is not to exactly determine the amount of strain. This would require a more extensive analysis of the area, and consideration of other, additional localisation mechanisms. Future work also needs to address how the instantaneous strain-rate distribution relates to that of the finite strain (compare Fig. 2b and d).

Shear localisation due to anisotropy appears almost inevitable when $A$ is large enough (here roughly $A \geq 4$ at $n \geq 3$ ). Localisation arises from the non-linear (both $A$ and $n>1$ ) constitutive law (Ord and Hobbs, 2018). Our results indicate that localisation is self-similar and does not average out over large scales or large strain increments. One reason for the lack of a characteristic scale is that the property anisotropy has no length scale. This sets localisation due to anisotropy apart from localisation mechanisms that do incorporate a length scale, such as shear heating (only effective at scales above the heat-diffusion length; e.g. Thielmann et al., 2015) and microstructural processes, such as grain-size reduction (e.g. de Bresser et al., 2001). 
Such mechanisms do not result in scale invariance and do not provide a single mechanism for the localisation of shear in small shear bands within larger shear zones.

Although the published range of strain localisation mechanisms can certainly all operate in rocks and ice, we show that mechanical anisotropy is a very effective additional mechanism. Self-similarity is a particular characteristic of this mechanism. This obviates the need to find individual mechanisms for strain localisation structures at different scales.

\section{Acknowledgements}

HR acknowledges financial support by the China Scholarship Council (CSC; grant nr. 201506400014). EGR acknowledges the support of the Beatriu de Pinós programme of the Government of Catalonia's Secretariat for Universities and Research of the Department of Economy and Knowledge (2016 BP 00208). M.-G.L acknowledges the support of the Juan de la Cierva programme of the Government of Spain's Ministry for Science, Innovation and Universities.

\section{References}

Anand, L., Kim, K.H., \& Shawki, T.G., 1987. Onset of shear localization in viscoplastic solids. Journal of the Mechanics and Physics of Solids, 35(4), 407-429.

Arbaret, L., Burg, J.P., Zeilinger, G., Chaudhry, N., Hussain, S., Dawood, H., 2000. Pre-collisional anastomosing shear zones in the Kohistan arc, NW Pakistan. Geological Society, London, Special Publications, 170, 295-311.

Bak, J., Korstgård, J., Sørensen, K., 1975. A major shear zone within the Nagssugtoqidian of West Greenland. Tectonophysics, 27, 191-209.

Bak, P., Tang, C., Wiesenfeld, K., 1987. Self-organized criticality: An explanation of the $1 /$ f noise. Physical review letters, 59, 381.

Behrmann, J.H., Mainprice, D., 1987. Deformation mechanisms in a high-temperature quartz-feldspar mylonite: evidence for superplastic flow in the lower continental crust. Tectonophysics, 140, 297-305.

Bell, T.H., 1981. Foliation development - the contribution, geometry and significance of progressive, bulk, inhomogeneous shortening. Tectonophysics, 75, 273-296.

Ben-Zion, Y., Sammis, C.G. 2003. Characterization of fault zones. Pure and Applied Geophysics, 160, 677-715.

Bercovici, D., 1993. A simple model of plate generation from mantle flow. Geophysical Journal International, 114, 635-650.

Berthé D., Choukroune, P., Jegouzo, P., 1979. Orthogneiss, mylonite and non-coaxial deformation of granites: the example from the South Armoricain shear zone. Journal of Structural Geology 1, 31-42.

Bird, P., 2003. An updated digital model of plate boundaries. Geochemistry, Geophysics, Geosystems, 4.

Bonnet, E., Bour, O., Odling, N.E., Davy, P., Main, I., Cowie, P., Berkowitz, B., 2001. Scaling of fracture systems in geological media. Reviews of geophysics, 39, 347-383.

Bons, P.D., Jessell, M.W., 1999. Micro-shear zones in experimentally deformed octachloropropane. Journal of Structural Geology, 21, 323-334. 
Bons, P.D., van Milligen, B.P., 2001. New experiment to model self-organized critical transport and accumulation of melt and hydrocarbons from their source rocks. Geology, 29(10), 919-922.

Bons, P.D., Druguet, E., Hamann, I., Carreras, J., Passchier, C.W. 2004. Apparent boudinage in dykes. Journal of Structural Geology, 26, 625-636.

Bons, P.D., Koehn, D., Jessell, M.W., 2008. Microdynamics Simulation, Volume 106 of Lecture Notes in Earth Sciences.

Bons, P.D., Jansen, D., Mundel, F., Bauer, C.C., Binder, T., Eisen, O., Jessell, M.W., Llorens, M.G., Steinbach, F., Steinhage, D., Weikusat, I., 2016. Converging flow and anisotropy cause large-scale folding in Greenland's ice sheet. Nature communications, 7, 11427.

Brown, M., Solar, G.S., 1998. Shear-zone systems and melts: feedback relations and self-organization in orogenic belts. Journal of Structural Geology, 20, 211227.

Brun, J.P., Cobbold, P.R., 1980. Strain heating and thermal softening in continental shear zones: a review. Journal of Structural Geology, 2(1-2), 149-158.

Brunetti, M.T., Guzzetti, F., Rossi, M., 2009. Probability distributions of landslide volumes. Nonlinear Processes in Geophysics, 16, 179.

Carreras, J., 2001. Zooming on Northern Cap de Creus shear zones. Journal of Structural Geology, 23, 1457-1486.

Carreras, J., Druguet, E., Griera, A., Soldevila, J., 2004. Strain and deformation history in a syntectonic pluton. The case of the Roses granodiorite (Cap de Creus, Eastern Pyrenees). Geological Society, London, Special Publications, 224, 307-319.

Carreras, J., Czeck, D.M., Druguet, E., Hudleston, P.J., 2010. Structure and development of an anastomosing network of ductile shear zones. Journal of Structural Geology, 32, 656-666.

Cobbold, P., 1976. Mechanical effects of anisotropy during large finite deformations. Bulletin de la Sociètè gèologique de France, 7, 1497-1510.

Cobbold, P.R., Cosgrove, J.W., Summers, J.M., 1971. Development of internal structures in deformed anisotropic rocks. Tectonophysics, 12, 23-53.

Cosgrove, J.W., 1976. The formation of crenulation cleavage. Journal of the Geological Society, 132, 155-178.

Cosgrove, J.W., 1997. The influence of mechanical anisotropy on the behaviour of the lower crust. Tectonophysics, 280, 1-14.

Dabrowski, M., Schmid, D.W., 2011. A rigid circular inclusion in an anisotropic host subject to simple shear. Journal of Structural Geology, 33(7), 1169-1177.

Dabrowski, M., Schmid, D.W., Podladchikov, Y.Y., 2012. A two-phase composite in simple shear: Effective mechanical anisotropy development and localization potential. Journal of Geophysical Research: Solid Earth, 117(B8).

Davy, P., Hansen, A., Bonnet, E., Zhang, S.Z., 1995. Localization and fault growth in layered brittle-ductile systems: Implications for deformations of the continental lithosphere. Journal of Geophysical Research: Solid Earth, 100, 6281-6294.

De Bresser, J.H.P., Peach, C.J., Reijs, J.P.J., Spiers, C.J., 1998. On dynamic recrystallization during solid state flow: Effects of stress and temperature. Geophysical Research Letters, 25, 3457-3460.

De Bresser, J., Ter Heege, J., Spiers, C., 2001. Grain size reduction by dynamic recrystallization: can it result in major rheological weakening? International Journal of Earth Sciences, 90, 28-45. 
Druguet, E., 2001. Development of high thermal gradients by coeval transpression and magmatism during the Variscan orogeny: insights from the Cap de Creus (Eastern Pyrenees). Tectonophysics, 332(1-2), 275-293.

Druguet, E., Hutton, D.H.W., 1998. Syntectonic anatexis and magmatism in a midcrustal transpressional shear zone: an example from the Hercynian rocks of the eastern Pyrenees. Journal of Structural Geology, 20(7), 905-916.

Druguet, E., Passchier, C.W., Carreras, J., Victor, P., Den Brok, S., 1997. Analysis of a complex high-strain zone at Cap de Creus, Spain. Tectonophysics, 280, 3145.

Duval, P., Ashby, M.F., Anderman, I., 1983. Rate-controlling processes in the creep of polycrystalline ice. The Journal of Physical Chemistry, 87, 4066-4074.

Estrin, Y., Kubin, L.P., 1991. Plastic instabilities: phenomenology and theory. Materials Science and Engineering, A137. 125 -134.

Finch, M.A., Weinberg, R.F., Hunter, N.J., 2016. Water loss and the origin of thick ultramylonites. Geology, 44, 599-602.

Fletcher, R.C., 2004. Anisotropic viscosity of a dispersion of aligned elliptical cylindrical clasts in viscous matrix. Journal of Structural Geology, 26, 19771987.

Fletcher, R.C., 2009. Deformable, rigid, and inviscid elliptical inclusions in a homogeneous incompressible anisotropic viscous fluid. Journal of Structural Geology, 31, 382-387.

Fossen, H., Cavalcante, G.C.G., 2017. Shear zones-A review. Earth-Science Reviews, 171, 434-455.

Fusseis, F., Handy, M.R., Schrank, C., 2006. Networking of shear zones at the brittleto-viscous transition (Cap de Creus, NE Spain). Journal of Structural Geology, 28 1228-1243.

Gapais, D., Bale, P., Choukroune, P., Cobbold, P., Mahjoub, Y., Marquer, D., 1987. Bulk kinematics from shear zone patterns: some field examples. Journal of Structural Geology, 9, 635-646.

Gardner, R., Piazolo, S., Evans, L., Daczko, N., 2017. Patterns of strain localization in heterogeneous, polycrystalline rocks-a numerical perspective. Earth and Planetary Science Letters, 463, 253-265.

Gómez Rivas, E., 2008. Localización de deformación en medios dúctiles y anisótropos. Unpublished PhD-thesis, Universitat Autònoma de Barcelona.

Gomez-Rivas, E., Griera, A., 2011. Strain rate influence on fracture development in experimental ductile multilayers. Tectonophysics, 502, 351-363.

Gomez-Rivas, E., Griera, A., 2012. Shear fractures in anisotropic ductile materials: an experimental approach. Journal of Structural Geology, 34, 61-76.

Gomez-Rivas, E., Griera, A., Llorens, M.G., 2015. Fracturing of ductile anisotropic multilayers: influence of material strength. Solid earth, 6(2), 497.

Gomez-Rivas, E., Griera, A., Llorens, M.G., Bons, P.D., Lebensohn, R.A., Piazolo, S., 2017. Subgrain Rotation Recrystallization During Shearing: Insights From Full-Field Numerical Simulations of Halite Polycrystals. Journal of Geophysical Research: Solid Earth, 122(11), 8810-8827.

Goncalves, P., Poilvet, J.-C., Oliot, E., Trap, P., Marquer, D., 2016. How does shear zone nucleate? An example from the Suretta nappe (Swiss Eastern Alps). J. Struct. Geol. 86, 166-180.

Griera, A., Bons, P.D., Jessell, M.W., Lebensohn, R.A., Evans, L., Gomez-Rivas, E., 2011. Strain localization and porphyroclast rotation. Geology, 39, 275-278. 
Griera, A., Llorens, M.G., Gomez-Rivas, E., Bons, P.D., Jessell, M.W., Evans, L.A., Lebensohn, R., 2013. Numerical modelling of porphyroclast and porphyroblast rotation in anisotropic rocks. Tectonophysics, 587, 4-29.

Gutenberg, B., Richter, C.F., 1956. Earthquake magnitude, intensity, energy, and acceleration: (Second paper). Bulletin of the seismological society of America, 46, 105-145.

Hähner, P., 1996. On the foundations of stochastic dislocation dynamics. Applied Physics A, 62, 473-481.

Hähner, P., Bay, K., Zaiser, M., 1998. Fractal dislocation patterning during plastic deformation. Physical review letters, 81, 2470.

Handy, M.R., 1990. The solid-state flow of polymineralic rocks. Journal of Geophysical Research 95, 8647-8661.

Handy, M.R., Mulch, A., Rosenau, M., Rosenberg, C.L., 2001. The role of fault zones and melts as agents of weakening, hardening and differentiation of the continental crust: a synthesis. Geological Society, London, Special Publications, 186, 305-332.

Hanmer, S., Passchier, C.W., 1991. Shear sense indicators: a review. Geological Survey of Canada Paper 90, $1 \pm 71$.

Herrmann, H.J., Poliakov, A.N., Tzschichholz, F., 1995. The deformation of rocks: fractals everywhere. Fractals, 3, 821-828.

Herwegh, M., Handy, M.R., 1996. The evolution of high-temperature mylonitic microfabrics: evidence from simple shearing of a quartz analogue (norcamphor). Journal of Structural Geology, 18, 689-710.

Hirth, G., Tullis, J., 1992. Dislocation creep regimes in quartz aggregates. Journal of Structural Geology, 14, 145-159.

Hippertt, J., 1999. Are S-C structures, duplexes and conjugate shear zones different manifestations of the same scale-invariant phenomenon?. Journal of Structural Geology, 21, 975-984.

Hobbs, B.E., Ord, A., 1988. Plastic instabilities: implications for the origin of intermediate and deep focus earthquakes. Journal of Geophysical Research, 93, 10,521-10,540

Hobbs, B.E., Mühlhaus, H.B., Ord, A., 1990. Instability, softening and localization of deformation. Geological Society, London, Special Publications, 54, 143-165.

Hudleston, P.J., 1999. Strain compatibility and shear zones: is there a problem?. Journal of Structural Geology, 21, 923-932.

Hudleston, P.J., Treagus, S.H., 2010. Information from folds: a review. Journal of Structural Geology, 32(12), 2042-2071.

Hull, J., 1988. Thickness-displacement relationships for deformation zones. Journal of Structural Geology, 10, 431-435.

Jansen, D., Llorens Verde, M.G., Westhoff, J., Steinbach, F., Kipfstuhl, S., Bons, P.D., Griera, A., Weikusat, I., 2016. Small-scale disturbances in the stratigraphy of the NEEM ice core: observations and numerical model simulations. The Cryosphere, 10, 359-370.

Jessell, M.W., Bons, P.D., Evans, L., Barr, T., Stüwe, K., 2001. Elle: the numerical simulation of metamorphic and deformation microstructures. Computers \& Geosciences, 27, 17-30.

Ji, S., Jiang, Z., Rybacki, E., Wirth, R., Prior, D., Xia, B., 2004. Strain softening and microstructural evolution of anorthite aggregates and quartz-anorthite layered composites deformed in torsion. Earth and Planetary Science Letters, 222, 377-390. 
Johnson, A.M., and Fletcher, R.C., 1994. Folding of viscous layers: mechanical analysis and interpretation of structures in deformed rock. Columbia University Press.

Johnson, S.E., Vernon, R.H., Upton, P., 2004. Foliation development and progressive strain-rate partitioning in the crystallizing carapace of a tonalite pluton: microstructural evidence and numerical modeling. Journal of Structural Geology, 26, 1845-1865.

Jordan, P., 1988. The rheology of polymineralic rocks - an approach. Geologische Rundschau, 77, 285-294.

Kocher, T., Schmalholz, S.M., Mancktelow, N.S., 2006. Impact of mechanical anisotropy and power-law rheology on single layer folding. Tectonophysics, 421(1-2), 71-87.

Kocher, T., Mancktelow, N.S., Schmalholz, S.M., 2008. Numerical modelling of the effect of matrix anisotropy orientation on single layer fold development. Journal of Structural Geology, 30(8), 1013-1023.

Latham, J.P., 1979. Experimentally developed folds in a material with a plannar mineral fabric. Tectonophysics, 57, T1-T8.

Lebensohn, R.A., 2001. N-site modeling of a 3D viscoplastic polycrystal using fast Fourier transform. Acta Materialia, 49, 2723-2737.

Lebensohn, R.A., Brenner, R., Castelnau, O., Rollett, A.D., 2008. Orientation imagebased micromechanical modelling of subgrain texture evolution in polycrystalline copper. Acta Materialia, 56, 3914-3926.

Lebensohn, R.A., Montagnat, M., Mansuy, P., Duval, P., Meysonnier, J., Philip, A., 2009. Modeling viscoplastic behavior and heterogeneous intracrystalline deformation of columnar ice polycrystals. Acta Materialia, 57(5), 1405-1415.

Llorens, M.G., Bons, P.D., Griera, A., Gomez-Rivas, E., Evans, L.A., 2013a. Single layer folding in simple shear. Journal of Structural Geology, 50, 209-220.

Llorens, M.G., Bons, P.D., Griera, A., Gomez-Rivas, E., 2013b. When do folds unfold during progressive shear? Geology, 41, 563-566.

Llorens, M.G., Griera, A., Bons, P.D., Roessiger, J., Lebensohn, R., Evans, L., Weikusat, I., 2016a. Dynamic recrystallisation of ice aggregates during coaxial viscoplastic deformation: a numerical approach. Journal of Glaciology, 62, 359-377.

Llorens, M.G., Griera, A., Bons, P.D., Lebensohn, R.A., Evans, L.A., Jansen, D., Weikusat, I., 2016b. Full-field predictions of ice dynamic recrystallisation under simple shear conditions. Earth and Planetary Science Letters, 450, 233242.

Llorens, M.G., Griera, A., Steinbach, F., Bons, P.D., Gomez-Rivas, E., Jansen, D.,Weikusat, I., 2017. Dynamic recrystallization during deformation of polycrystalline ice: insights from numerical simulations. Phil. Trans. R. Soc. A, 37520150346.

Mainprice, D., Nicolas, A., 1989. Development of shape and lattice preferred orientations: application to the seismic anisotropy of the lower crust. Journal of Structural Geology, 11(1-2), 175-189.

Mainprice, D., Bouchez, J.L., Blumenfeld, P., Tubià, J.M., 1986. Dominant c slip in naturally deformed quartz: implications for dramatic plastic softening at high temperature. Geology, 14(10), 819-822.

Mancktelow, N.S., Pennacchioni, G., 2004. The influence of grain boundary fluids on the microstructure of quartz-feldspar mylonites. Journal of Structural Geology, 26, 47-69. 
Mandelbrot, B.B., 2001. Scaling in financial prices: I. Tails and dependence. Quantitative Finance. Volume 1 - Issue 1

Mandelbrot, B.B., Fisher, A., Calvet, L., 1997. A multifractal model of asset returns.

Means, W.D., 1984. Shear zones of types I and II and their significance for reconstruction of rock history. Geol. Soc. Am. Bull. Abstract Programs, 16, 50 .

Menegon, L., Pennacchioni, G., Spiess, R., 2008. Dissolution-precipitation creep of K-feldspar in mid-crustal granite mylonites. Journal of Structural Geology, 30(5), 565-579.

Meyer, S.E., Kaus, B., Passchier, C., 2017. Development of branching brittle and ductile shear zones: A numerical study. Geochemistry, Geophysics, Geosystems, 18(6),2054-2075.

Michibayashi, K., Mainprice, D., 2004. The role of pre-existing mechanical anisotropy on shear zone development within oceanic mantle lithosphere: an example from the Oman ophiolite. Journal of Petrology, 45(2), 405-414.

Mitra, G., 1979. Ductile deformation zones in Blue Ridge basement rocks and estimation of finite strains. Geological Society of America Bulletin, 90, 935951.

Mitzenmacher, M., 2004. A brief history of generative models for power law and lognormal distributions. Internet mathematics, 1, 226-251.

Montagnat, M., Castelnau, O., Bons, P.D., Faria, S.H., Gagliardini, O., Gillet-Chaulet, F., Roessiger, J., 2014. Multiscale modeling of ice deformation behavior. Journal of Structural Geology, 61, 78-108.

Mühlhaus, H.B., Dufour, F., Moresi, L., Hobbs, B., 2002. A director theory for viscoelastic folding instabilities in multilayered rock. International Journal of Solids and Structures, 39, 3675-3691.

Oliot, E., Goncalves, P., Schulmann, K., Marquer, D., Lexa, O., 2014. Mid-crustal shear zone formation in granitic rocks: constraints from quantitative textural and crystallographic preferred orientations analyses. Tectonophysics, 612, 6380.

Ord, A., Hobbs, B., 2018. Quantitative measures of deformed rocks: The links to dynamics. Journal of Structural Geology.

Passchier, C.W., 1984. The generation of ductile and brittle shear bands in a lowangle mylonite zone. Journal of Structural Geology, 6, 273-281.

Passchier, C.W., Trouw, R.A., 2005. Microtectonics. Springer Science \& Business Media.

Pennacchioni, G., Mancktelow, N.S., 2007. Nucleation and initial growth of a shear zone network within compositionally and structurally heterogeneous granitoids under amphibolite facies conditions. J. Struct. Geol. 29, 1757-1780.

Platt, J.P., Behr, W.M., 2011. Grain size evolution in ductile shear zones: Implications for strain localization and the strength of the lithosphere. Journal of Structural Geology, 33, 537-550.

Poliakov, A.N.B., Herrmann, H.J., 1994. Self-organized criticality of plastic shear bands in rocks. Geophysical Research Letters, 21, 2143-2146.

Poliakov, A.N., Herrmann, H.J., Podladchikov, Y.Y., Roux, S., 1994. Fractal plastic shear bands. Fractals, 2, 567-581.

Poirier, J.P., 1980. Shear localization and shear instability in materials in the ductile field. Journal of Structural Geology, 2, 135-142.

Ponce, C., Druguet, E., Carreras, J., 2013. Development of shear zone-related lozenges in foliated rocks. Journal of Structural Geology, 50, 176-186. 
Qi, C., Prior, D.J., Craw, L., Fan, S., Llorens, M.-G., Griera, A., Negrini, M., Bons, P.D., and Goldsby, D.L., 2019. Crystallographic preferred orientations of ice deformed in direct-shear experiments at low temperatures, The Cryosphere Discuss. https://doi.org/10.5194/tc-2018-140

Ran, H., de Riese, T., Llorens, M.G., Finch, M.A., Evans, L.A., Gomez-Rivas, E., Griera, A., Jessell, M.W., Lebensohn, R.A., Piazolo, S., Bons, P. D., 2018. Time for anisotropy: The significance of mechanical anisotropy for the development of deformation structures. Journal of Structural Geology.

Ramsay, J.G., Allison, I., 1979. Structural analysis of shear zones in an alpinised Hercynian granite (Maggia Lappen, Pennine Zone, Central Alps). Schweizerische mineralogische und petrographische Mitteilungen, 59, 251-279.

Regenauer-Lieb, K., Hobbs, B., Ord, A., Gaede, O., Vernon, R., 2009. Deformation with coupled chemical diffusion. Physics of the Earth and Planetary Interiors, 172, 43-54.

Rice, J.R., 1976. The localization of plastic deformation. In Theoretical and Applied Mechanics (Proceedings of the 14th International Congress on Theoretical and Applied Mechanics, Delft). Vol 1, 207-220.

Rosenberg, C.L., Handy, M.R., 2000. Syntectonic melt pathways during simple shearing of a partially molten rock analogue (Norcamphor Benzamide). Journal of Geophysical Research: Solid Earth, 105, 3135-3149.

Sammis, C.G., Steacy, S.J., 1995. Fractal fragmentation in crustal shear zones. In Fractals in the Earth Sciences (pp. 179-204). Springer, Boston, MA.

Schrank, C. E., Handy, M. R., Fusseis, F., 2008. Multiscaling of shear zones and the evolution of the brittle-to-viscous transition in continental crust. Journal of Geophysical Research: Solid Earth, 113(B1).

Segall, P., Simpson, C., 1986. Nucleation of ductile shear zones on dilatant fractures. Geology, 14, 56-59.

Shea, W.T., Kronenberg, A.K. 1993. Strength and anisotropy of foliated rocks with varied mica contents. Journal of Structural Geology, 15, 1097-112.

Shimizu, I., 2008. Theories and applicability of grain size piezometers: The role of dynamic recrystallization mechanisms. Journal of Structural Geology, 30, 899917.

Sørensen, K., 1983. Growth and dynamics of the Nordre Strømfjord shear zone. Journal of Geophysical Research: Solid Earth, 88, 3419-3437.

Sornette, D., Pisarenko, V., 2003. Fractal plate tectonics. Geophysical research letters, $30(3)$.

Sornette, A., Davy, P., Sornette, D., 1993. Fault growth in brittle-ductile experiments and the mechanics of continental collisions. Journal of Geophysical Research: Solid Earth, 98, 12111-12139.

Steinbach, F., Bons, P.D., Griera, A., Jansen, D., Llorens Verde, M.G., Roessiger, J.,Weikusat, I., 2016. Strain localization and dynamic recrystallization in the ice-air aggregate: a numerical study. The Cryosphere, 10, 3071-3089.

Steinbach, F., Kuiper, E.J.N., Eichler, J., Bons, P.D., Drury, M.R., Griera, A., Pennock, G.M., Weikusat, I., 2017. The Relevance of Grain Dissection for Grain Size Reduction in Polar Ice: Insights from Numerical Models and Ice Core Microstructure Analysis. Frontiers in Earth Science, 5, 66.

Stipp, M., Stünitz, H., Heilbronner, R., Schmid, S.M., 2002. The eastern Tonale fault zone: a 'natural laboratory'for crystal plastic deformation of quartz over a 
temperature range from 250 to 700 C. Journal of Structural Geology, 24(12), 1861-1884.

Takeda, Y.T., Griera, A., 2006. Rheological and kinematical responses to flow of two-phase rocks. Tectonophysics, 427(1-4), 95-113.

Tchalenko, J. S., 1970. Similarities between shear zones of different magnitudes. Geological Society of America Bulletin, 81, 1625-1640.

Thielmann, M., 2018. Grain size assisted thermal runaway as a nucleation mechanism for continental mantle earthquakes: Impact of complex rheologies. Tectonophysics, 746, 611-623.

Thielmann, M., Kaus, B.J., 2012. Shear heating induced lithospheric-scale localization: Does it result in subduction?. Earth and Planetary Science Letters, 359, 1-13.

Thielmann, M., Rozel, A., Kaus, B.J.P., Ricard, Y., 2015. Intermediate-depth earthquake generation and shear zone formation caused by grain size reduction and shear heating. Geology, 43, 791-794.

Toimil, N.C., Griera, A., 2007. Influence of viscosity contrast and anisotropy on strain accommodation in competent layers. Journal of structural geology, 29(5), 787801.

Tommasi, A., Knoll, M., Vauchez, A., Signorelli, J. W., Thoraval, C., Logé, R., 2009. Structural reactivation in plate tectonics controlled by olivine crystal anisotropy. Nature Geoscience, 2, 423.

Treagus, S.H., 2003. Viscous anisotropy of two-phase composites, and applications to rocks and structures. Tectonophysics, 372(3-4), 121-133.

Tullis, J., Yund, R. A., 1985. Dynamic recrystallization of feldspar: A mechanism for ductile shear zone formation. Geology, 13, 238-241.

Turcotte, D.L., 1990. Implications of chaos, scale-invariance, and fractal statistics in geology. Palaeogeography, Palaeoclimatology, Palaeoecology, 89, 301-308.

Turcotte, D.L., 1992. Fractals, chaos, self-organized criticality and tectonics. Terra Nova, 4, 4-12.

Turcotte, D.L., 1997. Fractals and chaos in geology and geophysics. Cambridge university press.

Urai, J.L., 1983. Water assisted dynamic recrystallization and weakening in polycrystalline bischofite. Tectonophysics, 96(1-2), 125-157.

Warren, J.M., Hirth, G., 2006. Grain size sensitive deformation mechanisms in naturally deformed peridotites. Earth and Planetary Science Letters, 248, 438450.

Warren, J.M., Hirth, G., Kelemen, P.B., 2008. Evolution of olivine lattice preferred orientation during simple shear in the mantle. Earth and Planetary Science Letters, 272(3-4), 501-512.

White, S.H., Burrows, S.E., Carreras, J., Shaw, N. D., Humphreys, F.J., 1980. On mylonites in ductile shear zones. Journal of Structural Geology, 2, 175-187. 


\section{Appendix S.1. Equivalence between degree of anisotropy $(A)$ and classical viscous anisotropy $(\delta)$}

The degree of anisotropy $A$ was defined as the ratio of the critical resolved shear stresses of the non-basal and basal slip systems (Eq. 2). This definition differs from the classical definition of viscous anisotropy $\delta$ as the ratio of the normal $\left(\mu_{n}\right)$ and shear viscosities $\left(\mu_{s}\right)$. However, both definitions are equivalent as is demonstrated below.

From the constitutive equation of a non-linear incompressible viscous ratedependent material (Eq. 1), the strain rate $\dot{\varepsilon}(\boldsymbol{x})$ is the sum of the resolved shear strain rate $\dot{\gamma}^{S}(\boldsymbol{x})$ and shear stress $\tau^{S}(\boldsymbol{x})$ over all the $N_{s}$ slip systems,

$\dot{\varepsilon}(\boldsymbol{x})=\sum_{s=1}^{N_{s}} m^{s}(\boldsymbol{x}) \dot{\gamma}^{s}(\boldsymbol{x})=\dot{\gamma}_{0} \sum_{s=1}^{N_{s}} m^{s}(\boldsymbol{x})\left(\frac{\tau^{s}(\boldsymbol{x})}{\tau_{0}^{s}}\right)^{n}$

where $m^{s}(\boldsymbol{x})=\frac{1}{2}\left(n^{s}(\boldsymbol{x}) \otimes b^{s}(\boldsymbol{x})+b^{s}(\boldsymbol{x}) \otimes n^{s}(\boldsymbol{x})\right)$ is the symmetric Schmid tensor ( with $n^{s}(\boldsymbol{x})$ and $b^{s}(\boldsymbol{x})$ being the normal and Burgers vectors of the slip system $s), \dot{\gamma}_{0}$ is the reference shear strain-rate and $\tau_{0}^{S}$ is the critical resolved shear stress in the slip system $s$. In this study, ice Ih with basal and non-basal slip systems was used. Equation S1 can be arranged in both sets of slip systems,

$$
\begin{aligned}
& m^{\text {basal }}(\boldsymbol{x}) \dot{\gamma}^{\text {basal }}(\boldsymbol{x})+\sum_{\text {non-basal }} m^{s}(\boldsymbol{x}) \dot{\gamma}^{s}(\boldsymbol{x}) \\
& =\dot{\gamma}_{0} m^{\text {basal }}(\boldsymbol{x})\left(\frac{\tau^{\text {basal }}(\boldsymbol{x})}{\tau_{0}^{\text {basal }}}\right)^{n}+\dot{\gamma}_{0} \sum_{\text {non-basal }} m^{s}(\boldsymbol{x})\left(\frac{\tau^{s}(\boldsymbol{x})}{\tau_{0}^{s}}\right)^{n}
\end{aligned}
$$

Note that the resolved shear stress of a slip system is the projection of the deviatoric stress field $\sigma^{\prime}(\boldsymbol{x})$ onto the slip system through the Schmid tensor (i.e. Schmid law, $\tau^{s}(\boldsymbol{x})=m^{s}(\boldsymbol{x}): \sigma^{\prime}(\boldsymbol{x})$ ). In a simplified form, the resolved shear stress on the slip system $s$ depends on the relative angles between the tensile axis and the normal of the slip plane $(\varphi)$ and the slip direction $(\lambda)$, $\tau^{s}(\boldsymbol{x})=\sigma^{\prime}(\boldsymbol{x}) \cos \varphi \cos \lambda \quad(S 3)$.

For the case of simple shear deformation parallel to the basal plane and a shear direction parallel to basal slip direction, the resolved shear stress is maximum for the basal plane while it tends to zero for non-basal planes. Therefore, equation S2 evolves to

$m^{\text {basal }}(\boldsymbol{x}) \dot{\gamma}^{\text {basal }}(\boldsymbol{x})=\dot{\gamma_{0}} m^{\text {basal }}(\boldsymbol{x})\left(\frac{\tau^{\text {basal }}(\boldsymbol{x})}{\tau_{0}^{\text {basal }}}\right)^{n}=\frac{\dot{\gamma_{0}} m^{\text {basal }}(\boldsymbol{x})}{\tau_{0}^{\text {basal }}} \tau^{\text {basal }}(\boldsymbol{x})^{n}$

After rearrangement,

$\dot{\gamma}^{\text {basal }}(\boldsymbol{x})=\frac{\dot{\gamma_{0}}}{\tau_{0}^{\text {basal }}{ }^{n}} \tau^{\text {basal }}(\boldsymbol{x})^{n}=B \tau^{\text {basal }}(\boldsymbol{x})^{n}(S 5)$,

the equation is equivalent to the classical expression of a non-linear viscous material, with $B$ a pre-exponential constant. For the case of effective viscosity (i.e. a linear relationship between shear strain rate and stress, $n=1$ ), the shear viscosity is equivalent to the inverse of $B$,

$\mu_{s}=\frac{1}{B}=\frac{\tau_{0}^{\text {basal }}}{\dot{\gamma_{0}}}(S 6)$. 
For the case that the strain rate axes are parallel and normal to the basal plane (i.e. pure shear), the relation between stress and strain rate is through the normal viscosity $\left(\mu_{n}\right)$. For this case, the resolved shear stress is zero for the basal plane $(\varphi=90$ if shortening normal to the base plane or $\lambda=90$ if shortening is parallel to the base plane) and deformation is fully accommodated by non-basal systems. Therefore, equation S2 is now,

$$
\sum_{n o n-b a s a l} m^{s}(\boldsymbol{x}) \dot{\gamma}^{s}(\boldsymbol{x})=\dot{\gamma}_{0} \sum_{n o n-b a s a l} m^{s}(\boldsymbol{x})\left(\frac{\tau^{s}(\boldsymbol{x})}{\tau_{0}^{s}}\right)^{n}
$$

And following similar development as in the previous case, the normal viscosity is related to the critical resolved shear stress of the non-basal systems through the pre-exponential $B$.

$\mu_{n}=\frac{1}{B}=\frac{\tau_{0}^{\text {non-basal }}}{\dot{\gamma}_{0}} \quad(S 8)$.

Finally, the viscous anisotropy $\delta$ of the system is

$\delta=\frac{\mu_{n}}{\mu_{s}}=\frac{\tau_{0}^{\text {non-basal }}}{\tau_{0}^{\text {basal }}}=A(S 9)$,

and is therefore identical to the degree of anisotropy $A$. 